\title{
Scarring alopecia in neonates as a consequence of hypoxaemia-hypoperfusion
}

\author{
Lynn A Gershan, Nancy B Esterly
}

\begin{abstract}
Scarring alopecia is relatively uncommon in infants and children and rarely discussed in the paediatric literature. It does not appear to have been previously documented as a consequence of compromised oxygenation and blood supply in the neonatal population or as a complication of extracorporeal membrane oxygenation (ECMO) treatment. During a six month period, we observed five patients who presented to our neonatal intensive care unit with pressure ulcers that eventuated in scarring alopecia. The patients were all $\geqslant 2500 \mathrm{~g}$ at birth, had some disruption of the cardiac circulation, were hypoxaemic and acidotic, and required vasopressor treatment. Institution of a positioning schedule and use of a thermostable Spenco gel pad during the subsequent six month period eliminated the presence of pressure ulceration and scarring alopecia in this at-risk population.
\end{abstract}

Although scarring alopecia is a permanent condition, skin changes preceding its development in this setting are recognisable and follow a predictable pattern and time course, and should therefore allow for intervention at an earlier stage. Neonatal ECMO patients, as well as those who suffer hypoxaemia-hypoperfusion, but do not require circulatory bypass, appear to be at increased risk for development of the pressure ulcers that precede scarring alopecia. Paediatricians should consider this possibility and seek the appropriate historical information when confronted with a case of scarring alopecia after the neonatal period.

(Arch Dis Child 1993; 68: 591-593)

Scarring alopecia may occur as a feature of a hereditary syndrome, as a developmental defect, or secondary to a multitude of causes including infections, tumours, and burns. We have found, however, no reports of scarring alopecia resulting from pressure ulcers after either extracorporeal membrane oxygenation (ECMO) or hypoxaemia-hypoperfusion in the neonatal period. Pressure ulcers in a group of older infants and children after open heart surgery is reported by Neidig et al but they do not mention scarring alopecia as an outcome. ${ }^{1}$ They delineate four risk factors for pressure ulcers: age, type of congenital heart defect, duration of intubation, and length of stay in the paediatric intensive care unit.

Pressure ulcers result from interference with nutrient blood supply to specific body tissues.
Factors that influence their development include: pressure transmitted to the tissue, tissue oxygenation, local environment, and the general state of health and mobility of the patient, ${ }^{2}$ all of which appear to be at work in the setting of the critically ill newborn. Whether oi not the ulceration progresses to scarring alopecia depends on the duration of the insult, the physiological state of the newborn, early recognition, and the effectiveness of preventive measures.

\section{Patients, methods, and results}

We examined five infants in our neonatal intensive care unit who were hospitalised between 1 August 1990 and 28 February 1991, who were recovering from episodes of hypoxaemia-hypoperfusion, and had occipital ulcers that progressed to scarring alopecia (figs 1-3). Review of their medical records yielded the clinical data summarised in the table.

\section{Discussion}

Scarring alopecia results from combined destruction of the hair follicles and fibrosis of the reticular dermis. ${ }^{3}$ No new follicles are formed after birth, hence the irreversibility of this process and the importance of its differentiation from the temporary condition of postoperative pressure alopecia. Studies of risk factors for pressure ulceration in adults and older paediatric patients are not applicable to our sick newborn population. Many of our patients have a long stay in the neonatal intensive care unit and are intubated for prolonged periods but do not develop either pressure ulcers or permanent hair loss. The goal in reviewing these five cases that demonstrated a rapid progression to loss of skin integrity and the sequela of scarring alopecia was to attempt to identify risk factors that would allow early recognition and intervention in future neonatal patients.

\section{PATHOPHYSIOLOGY}

Adults who experience immobilisation of the head for 24 hours or longer develop not only occipital ulceration but also scarring. ${ }^{4}$ The duration of exposure to pressure and shearing forces that leads to localised ischaemia appears to determine whether ulceration will be temporary or progress to permanent alopecia in this population. ${ }^{56}$ Comparable data are not available for paediatric or neonatal patients.

There is evidence that obstructed capillary blood flow in the skin, with subsequent tissue ischaemia and hypoxaemia, appears to be of 


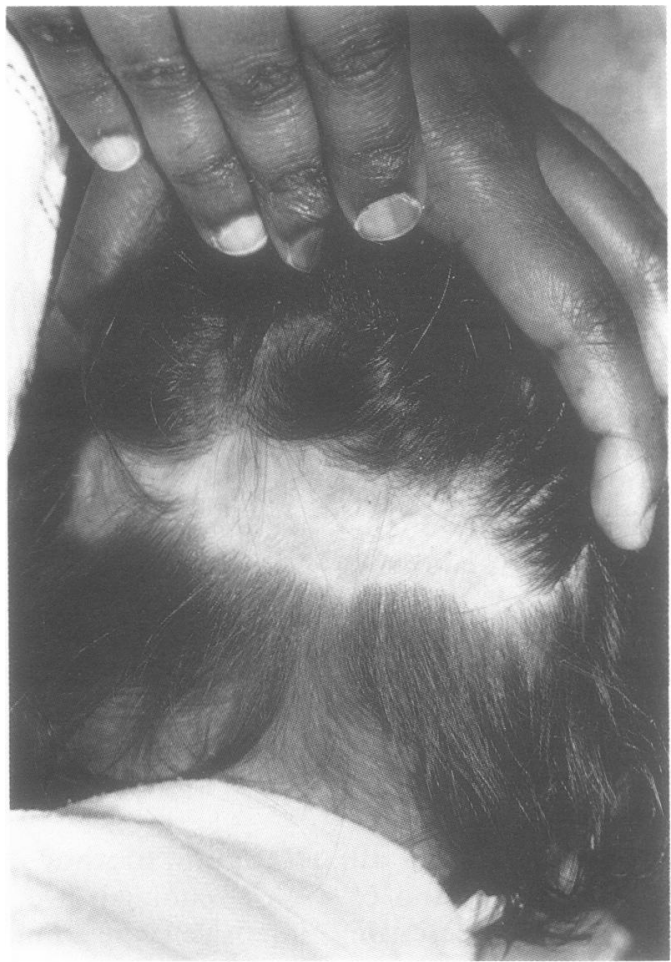

Figure 1 View of occipital area of scalp in 12 month old boy (case 1) illustrating scarring alopecia. Dermatological consultation was requested by the parents at the time of this admission.

greater importance than venous occlusion in producing injury. ${ }^{78}$ Our patients required cardiopulmonary resuscitation, pressor support (that shunts blood from the peripheral to the central circulation), large and small vessel arterial and venous cannulation, and inflow occlusion during cardiac surgery. These interventions provide several means whereby the capillary skin perfusion at the arterial inflow site could have been compromised, and thrombosis and embolisation leading to ulceration may have occurred.

Scalp biopsy samples in adult patients reveal consistent pathological changes ranging from perivascular inflammation, oedema, and intravascular thrombosis in the early stages to obliterative-degenerative vasculitis, and panniculitis involving the deep dermal and subcutaneous tissues later in the course. ${ }^{59}$ These

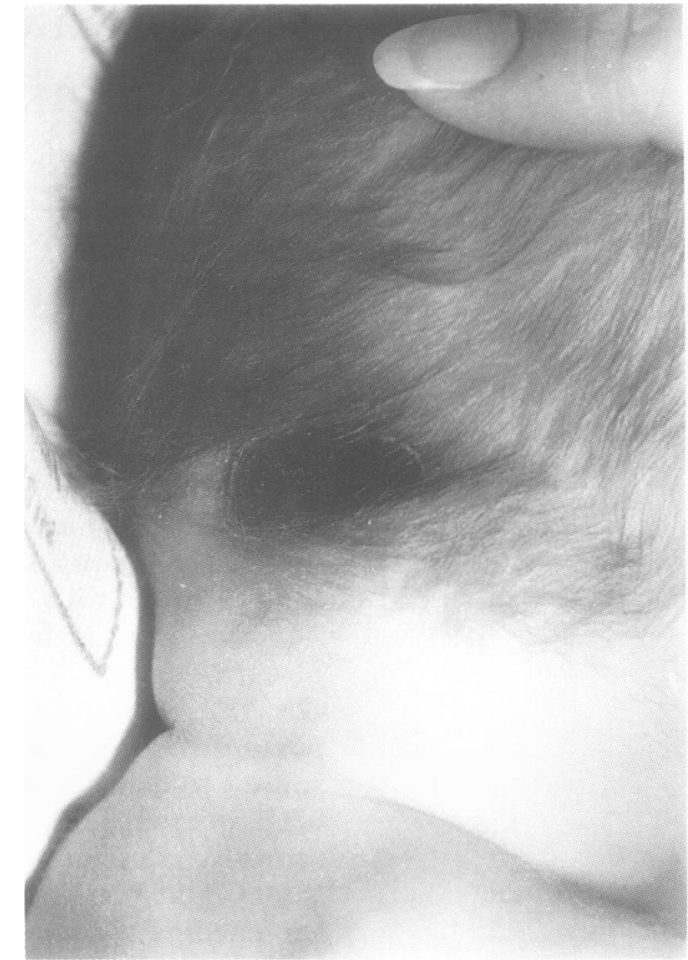

Figure 2 Right occipital view of scalp from patient in case 2 demonstrating eschar formation by day 17. Position changes with gel and sheepskin support behind the head were instituted at this time.

changes were undoubtedly present in our five neonatal patients; however, biopsies were not obtained as we did not believe the findings would have altered management.

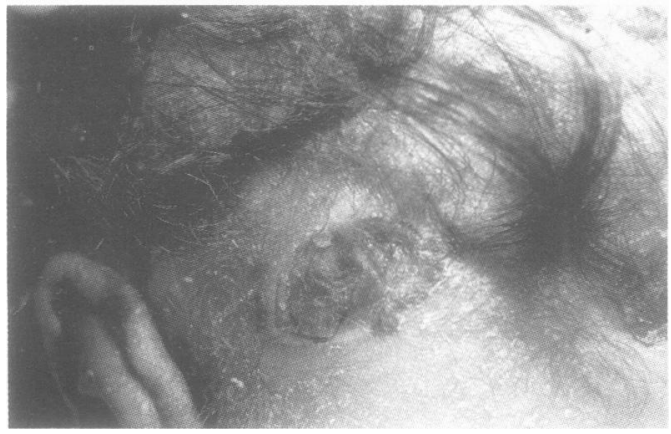

Figure 3 View of left occipital area from patient described in case 5, illustrating ulcer formation on day 28.

Diagnosis and characteristics of neonatal patients who developed scarring alopecia

\begin{tabular}{|c|c|c|c|c|c|}
\hline & Patient 1 & Patient 2 & Patient 3 & Patient 4 & Patient 5 \\
\hline $\begin{array}{l}\text { Birth weight }(g) \\
\text { Sex }\end{array}$ & $\begin{array}{l}3085 \\
\text { Male }\end{array}$ & $\begin{array}{l}2520 \\
\text { Female }\end{array}$ & $\begin{array}{l}2500 \\
\text { Male }\end{array}$ & $\begin{array}{l}3400 \\
\text { Female }\end{array}$ & $\begin{array}{l}2693 \\
\text { Female }\end{array}$ \\
\hline Diagnosis & $\begin{array}{l}\text { Group B streptococcus, } \\
\text { septicaemia, pul- } \\
\text { monary interstitial } \\
\text { emphysema }\end{array}$ & $\begin{array}{l}\text { Pulmonary atresia, renal } \\
\text { failure, hepatitis }\end{array}$ & $\begin{array}{l}\text { Critical pulmonary } \\
\text { stenosis }\end{array}$ & $\begin{array}{l}\text { Meconium aspiration, } \\
\text { pulmonary hyperten- } \\
\text { sion }\end{array}$ & $\begin{array}{l}\text { Patent ductus arteriosus, } \\
\text { T cell deficiency }\end{array}$ \\
\hline Acidosis & + & + & + & + & + \\
\hline Albumin $\leqslant 27 \mathrm{~g} / 1$ & + & + & - & + & + \\
\hline Arrhythmia & - & + & - & - & + \\
\hline Cardiac arrest/shock & + & + & - & - & + \\
\hline Coagulation disturban $\mathrm{e}^{\star}$ & + & + & - & + & + \\
\hline Disruption of cardiac circulation $\dagger$ & + & + & + & + & + \\
\hline Hypoxaemia & + & + & + & + & + \\
\hline Infection, systemic & + & - & - & + & + \\
\hline $\begin{array}{l}\text { Prolonged neuromuscular block- } \\
\text { ade }\end{array}$ & + & - & - & - & -. \\
\hline Vasopressor treatment & + & + & + & + & + \\
\hline $\begin{array}{l}\text { White cell count on admission } \\
<8 \times 10^{\circ} \text { cells } / 1\end{array}$ & + & - & - & + & - \\
\hline
\end{tabular}


DEVELOPMENTAL ASPECTS

Certain peculiarities of the fetal-neonatal hair cycle may have facilitated the development of scarring alopecia in our patients. The hairs of the occipital follicles undergo one cycle of shedding in utero and remain in the anagen (growth) phase as the rest of the scalp hair enters the telogen (resting) phase preparatory to routine postnatal shedding. 10

The anagen phase of hair growth is characterised by an extreme sensitivity to noxious influences. Minor trauma can stimulate the simultaneous conversion of many follicles to telogen resulting in visible temporary alopecia. In the face of more extensive injury, mitosis is disrupted and the hairs are lost while still in the anagen phase; permanent damage to the follicle may then result. This increased sensitivity of the anagen follicle to compromised conditions such as hypoxaemia and hypoperfusion may account for the severe damage that occurred to the scalps of these infants.

\section{PREVENTION}

Prevention is the most effective approach to the problem of pressure ulceration and its potential sequelae. Progression from erythema, swelling, and crusted ulceration to hair loss is reported by Lawson et al in their adult surgical patients. Alopecia was obviated by 30 minute rotations of the head during the period of immobilisation. $^{9}$ Increased awareness of cutaneous changes associated with localised pressure effects is imperative and should include skin monitoring for: pallor (early), oedema, hyperaemia (later), and local changes in skin temperature indicative of altered metabolic demands. ${ }^{11}$ The appearance of nonblanchable erythema and disruption of the epidermis should signal the need for immediate intervention. Postural changes and passive range of motion will alter pressure distribution and improve local blood flow.

Patients on ECMO with restricted head movements due to the neck cannulae and those with decreased movement secondary to sedation, neurological impairment, or pharmacological neuromuscular blockade should have a scheduled head, trunk, and extremity rotation that does not interfere with other nursing care routines. Nutrition management is an integral part of care in any critically ill patient and meticulous attention to details, such as adequate intake of vitamins (for example, vitamin $A$ is important for secondary wound repair) and trace metals (for example, zinc is vital to wound healing) has obvious benefits. Alcohol and similar astringents should be avoided as they can cause vasoconstriction in already ischaemic areas and may also remove protective skin surface barrier lipids.

After our initial observations, the nursing staff in our neonatal intensive care unit (that has a stable referral base of cardiac, surgical, and post-ECMO patients) implemented care plans emphasising positioning of patients and use of a temperature stable gel pad (Spenco) placed behind the head. During the six months since these changes were instituted, we have had no patients (including seven ECMO patients) with pressure ulcerations and no cases of scarring alopecia. Plans to institute these preventive measures in the paediatric intensive care unit, where much of the initial care of these infants takes place, are currently underway.

\section{CONCLUSION}

From our review of these five infants, we conclude that the requirement for vasopressor treatment in the presence of hypoxaemia and acidosis in the term neonate is strongly associated with risk of development of scarring alopecia. The prolonged period of head immobilisation associated with ECMO may confer additional risk. Although the pathogenesis of scalp necrosis and subsequent scarring may not be completely elucidated in the neonatal population, if clinical conditions associated with increased risk are recognised and the predictable sequence of events is terminated at an early stage, an adverse outcome may be prevented.

The events leading to scarring alopecia may be readily apparent to the attending physician during the immediate neonatal period. If such a patient is seen at a later date, however, the examining physician may be unaware of circumstances of the perinatal period, and may, therefore, consider a more extensive differential diagnosis. ${ }^{3}$ Evaluation of scarring alopecia requires a careful history with attention to details involving cardiovascular compromise and oxygenation, the role of trauma or chemical injury, and a thorough examination of the skin and hair of the rest of the body. A scalp biopsy may sometimes be required to exclude other disease processes. Definitive treatment of scarring alopecia usually involves surgical excision of the affected area that further emphasises the irreversibility of this final stage.

Avoidance of permanent damage to skin and hair follicles may seem trivial in the schema of the life saving technology of an intensive care unit, but scarring alopecia and other cosmetic defects may have a long lasting effect on the psychological well being of our patients and their parents and should not be ignored.

1 Neidig JRE, Kleiber C, Oppliger RA. Risk factors associated with pressure ulcers in the pediatric patient following open-heart surgery. Progress in Cardiovascular Nursing
1989; 4: 99-106.

2 Reuler JB, Cooney.TG. The pressure sore: pathophysiology and principles of management. Ann Intern Med 1981; 94: 661-6.

3 Newton RC, Hebert AA, Freese TW, Solomon AR. Scarring alopecia. Dermatol Clin 1987; 5: 603-18.

4 Maklebust J. Pressure ulcers: etiology and prevention. Nurs Clin N Am 1987; 22: 359-77.

5 Abel RR, Lewis GM. Postoperative (pressure) alopecia. AMA Archives of Dermatology 1960; 81: 31-42.

Wiles JC, Hansen RC. Postoperative (pressure) alopecia. f Am Acad Dermatol 1985; 12: 195-8.

Landis E. Studies of capillary blood pressure in human skin. Heart 1930; 15: 209-28.

8 Lindan O. Etiology of decubitus ulcers: an experimental study. Arch Phys Med Rehabil 1961; 42: 774-83.

9 Lawson NW, Mills NL, Ochsner JL. Occipital alopecia following cardiopulmonary bypass. $\mathcal{f}$ Thorac Cardiovasc Surg 1976; 71: 342-7.

10 Rook A, Dawber R. The hair in infancy and childhood. Diseases of the hair and scalp. Oxford: Blackwell Scientific Diseases of the hair and scalp.
Publications, 1982: 49-62.

11 Constantian MB, Jackson HS. Biology and care of the pressure wound. In: Constantian MB, ed. Pressure ulcers: principles and techniques of management. Boston: Little, principles and techniques of managem 